\title{
THE SWANSEA UNIVERSITY BLENDED LEARNING PILOT
}

\author{
P. Holland, K. Ennser, S. Cahill, M. Hainke, E. Moriarty, R. Kerton \\ Swansea University (UNITED KINGDOM)
}

\begin{abstract}
The Higher Education (HE) sector in the United Kingdom has seen significant changes in recent years with higher student fees, removal of the cap on student numbers and the introduction of the Teaching Excellence Framework to benchmark teaching quality across the country. Swansea University management has recognised these fast-changing and complex demands on the HE sector and has responded by introducing strategy, organisational changes and initiatives. These have included a teaching and scholarship academic career pathway, a focus on improving training and recognition for staff innovation in teaching practice.
\end{abstract}

One of the effects of these interventions was the organic growth in the use of blended approaches, showing positive student feedback and the emerging evidence of improved performance - these positive effects aligned with sectoral developments in independent learning, student co-creation, and enhanced digital capabilities. However, the change to increased adoption of such online learning approaches led to broader considerations of how the institution should best support it, how to manage the risk of unintended consequences and consistency of practice issues and the impact on IT services in terms of software systems and cybersecurity.

To provide answers to these considerations and to support further growth, an institution-wide pilot project was designed and ran from August 2017 to March 2019. The design of the Blended Learning Pilot project was such that it maintained the spirit and freedom of the previous organic growth but wrapped institutional support around it, continuing the natural innovation and departmental ownership. Staff volunteers wanting to trial blended learning were encouraged, trained and given access to appropriate hardware and software tools.

In this work, we will present the outputs of the pilot, where over 50 academic volunteers converted 92 modules to a blended learning format reaching over 6,555 students. We will describe a range of achieved outputs and the lessons learned that will help institutions wishing to support or increase the use of blended learning successfully.

Keywords: Blended Learning, Flipped Learning, Active Learning, TEL.

\section{INTRODUCTION}

Perhaps in the latter half of the $20^{\text {th }}$ century, the models for learning and teaching in higher education in the United Kingdom (UK) were well understood where collated knowledge and understanding passed from expert lecturers and professors to academically minded students. Students were able to access well-stocked libraries, attend their lectures and burn the midnight oil, feeding their passion for knowledge with financial security supplied by maintenance grants and government-funded tuition fees. Around the start of the $21^{\text {st }}$ century, several factors began to interrupt business as usual, and now in 2019, there is significant change happening across the UK and global higher education (HE) sector.

The digital age has truly arrived over the last ten years, where now broadband speeds, 3G+ mobile standards and $\mathrm{Wi}-\mathrm{Fi}$ technology are pervasive. The improved communications, enabled by massive improvements in the processing power of microcomputer chips arrived in tandem with smart device technologies, where for example the iPhone was released in 2007, and the Samsung Galaxy and iPad tablets in 2010. It is becoming increasingly apparent year by year that young people entering HE and who have grown up with digital technology have high expectations of flexible online learning [1, 2].

Other factors that have impacted on education in the UK include the significant increase in the number of young people entering HE. In 1999, the then Prime Minister Tony Blair pledged that $50 \%$ of young people would be able to progress to HE by 2010 with aims of equality, social mobility and to eliminate poverty. While our academic colleagues in humanities, politics and economics may debate the effectiveness of these aims, there is no doubt the policy successfully met its goals of increasing 
participation. The UK's Universities and Colleges Admissions Service (UCAS) announced record numbers of young people entering HE in Wales and England in 2017 while in 2018 there has only been a reduction of $1 \%$ of students enrolling on courses despite a $2.5 \%$ reduction in the number of 18-year-olds obiobithe UK in 2018, the Department for Education estimated the likelihood of a young person participating in $\mathrm{HE}$ by age 30 , based on current participation rates this number has increased to $49.8 \%$ [ise learning and teaching practice and the broader landscape where approaches to increase inclusivity and improve accessibility are markers of institutional reputation and quality.

The more recent impetus for change in the UK HE sector has included the introduction of $£ 9000$ fees in 2012/2013 [6], the removal of the cap on student numbers from 2015 / 2016 [7], and the introduction of the Teaching Excellence Framework (TEF) where the first ratings were published in 2017 and more recently linked to increases in tuition fees [8]. These government interventions were designed to bring private sector innovation and continue to fund universities during the period of austerity after the economic crash of 2007. Again, the debate about the wisdom of such interventions will continue, but it is clear that unleashing market forces have increased competition between universities to recruit students [9]. Student voice and the perception of value for money are increasingly driving university strategies with visible investment in physical and digital estate funded by private equity. With some students emerging with significant personal debt, the value of a university education is increasingly under scrutiny with other models such as degree apprenticeships seen as a viable alternative by some and providing further stimulus for universities to consistently provide high quality student experience [10].

Our senior management team and colleagues in the Swansea Academy for Learning and Teaching (SALT) recognising these fast-changing and complex demands on the UK HE sector have introduced strategy, organisational changes and initiatives including a teaching and scholarship academic career pathway; an internal HEA Fellowship awarding route, a PGCert for new academic staff and a comprehensive CPD programme.

The effect of these interventions was to increase innovation; academics experimented with combining face-to-face and online learning delivery or what is commonly termed blended learning. This approach organically grew across the institution and reached a critical mass requiring further attention. The strong positive effects on student learning and experience in the modules of blended learning pioneers became evident but so too the challenges associated with maintaining consistency of learning and teaching practice, supporting diverse digital tools and creating a supportive environment for wider growth.

The Heads of Colleges at Swansea University (SU) decided to financially support blended learning under a common purpose and through discussions across the University, initiated the SU Blended Learning Pilot. The Pilot aimed to provide answers to above challenges through staff volunteers working together as a community of practice.

This paper describes the approach taken to successfully deliver the Swansea University Blended Learning Pilot, including funding, volunteer recruitment, project aims, objectives and the results obtained. We show that with careful planning, it is possible to run successful institutional wide learning and teaching projects. Five recommendations are given in the conclusions for institutional adoption of blended learning with extra insights on lessons learned for other institutions considering similar initiatives.

\section{APPROACH AND DELIVERY}

\subsection{Project Ethos}

A project planning team was formed and led by the University's Dean of Educational Technology and staff from the Planning and Strategic Projects Unit (PSPU). After consultation with stakeholders across the University, it was decided to create a pilot project that would build on previous growth of blended learning but leave ownership with colleges and departments. While the approach to wider adoption of blended learning, therefore, leans more towards the 'second way' described by Gilly Salmon where adoption is more incremental [7], staff wanting to trial blended learning were fully supported by a central team with encouragement, training and access to appropriate tools. 


\subsection{Project Development, Aims and Objectives}

A project proposal was written and presented to Swansea University's Common Purpose Committee with a clearly stated approach, scope, aims, deliverables, outputs, outcomes and impact goals. The budget for the one-year project covered the salaries for a project manager, a learning technologist (LT) to cover more general training and support of blended learning and a second LT to work alongside existing specialists in supporting virtual and augmented reality interventions.

The approach was to convert 10-12 modules per college to a blended learning offering to give a total of approximately 70 modules across the institution; enough to capture outputs and deliverables yet still manageable by a small team. Each college agreed to identify an academic champion already engaged with blended learning, keeping the movement towards blended learning in the hands of the pioneers and early adopters.

The project aims and deliverables were aligned to support the move to blended learning where the pilot would provide the 'definition' of blended learning; an educational framework to describe systems and training and a roadmap to guide university-wide growth and adoption if the pilot indicated merit in doing so. The outputs detailed the number of modules converted; impact on attendance; exam performance versus engagement; the number of trained staff and variety of educational approaches used. Measurable outcomes included student experience, student performance, the balance of delivery methods (face-to-face and online) and related scholarship and pedagogic research outputs.

\subsection{Formation of the Operational Team}

A recruitment process enabled the formation of the full team of Project Manager, Learning Technologists, College Academic Champions, Head of the Learning and Teaching Enhancement Centre (LTEC) and Dean of Educational Technology. Through careful planning, the team embedded the project ethos and approach into the day-to-day activities of the delivery phase. While the project proposal was written in precise and metric-driven terms, a decision was taken not to impose formal project management approaches. The move to blended learning was a movement driven by core values and the willingness of staff to work with students to improve their learning and teaching practice. The team adopted a supportive hands-off approach maintaining that spirit by providing initial guidance, training and communications to start the project, with the College Academic Champions then developing communities of practice in each college. By continuing help through guidance and further training, assistance was available through the full term of the project; however, this was never mandatory or imposed. A frequently asked questions (FAQs) document was carefully written to describe the project aims and its ethos to support bottom-up growth to help recruit academic volunteers who were willing to trial blended learning. This reassuring and genuine approach was successful, and the colleges recruited staff volunteers onto the project in a coordinated and transparent way.

\subsection{College Landscapes and Opportunities}

In a medium-size HE institution with many departments and seven colleges, each academic champion encountered different learning and teaching cultures, thus requiring tailored approaches. Working through many challenges the team recognised that any problem is also an opportunity. They found solutions to improve the learning environment and blended learning capability for the long term. For example, when writing the project bid it was assumed each college would operate in the same way and keep a set of laptops for staff to loan. While this was the case in the larger colleges it was not the case for the College of Arts and Humanities, and there was a delay in supplying a set of suitable kit for their staff to be able to produce their blended learning content. However, resolving this issue now means there are laptops available for staff in all our colleges. Additionally, while resolving this issue, the team established a bookable fully kitted editing studio for staff and students to create content in quiet spaces.

In the College of Engineering (CoE), the focus of the pilot was on the use of Virtual Reality (VR) in teaching where all ten Blended Learning Pilot modules had a VR intervention. However, our CoE champion, found it challenging to find enough suitable learning spaces to set up the VR equipment requiring multiple sessions in small CoE spaces so all our students in the larger cohorts could participate. By working with the CoE management and the Estates department, delivery of VR interventions now occurs in a repurposed and dedicated space. The new space enables the implementation of more VR interventions going forward. 
Another example of effective teamwork was the acquisition of a site-wide licence for video production software, Camtasia ${ }^{\mathrm{TM}}$. Many staff in the pilot fed back their desire, and in some cases, their students desire to produce videos enabling the creation of video content. Individually, colleges had bought licenses, duplicating effort and not benefitting from the economy of scale. Investing in a site licence for staff enabled savings of thousands of pounds, and through negotiations, the licence extended for student use. There is now a powerful University-wide software to enable both students and staff to develop their digital skills and open the potential of using videos in learning, teaching and assessment. For example, colleagues are introducing the use of student-produced promotional videos to help assess third-year projects and to share with prospective students on the website and during open days.

\section{RESULTS AND DISCUSSION}

\subsection{Project Headline Results}

From an initial 100 interested staff, 80 joined and undertook training to enhance their digital skills and capabilities. In total, 53 staff completed the final survey and collectively delivered 92 blended modules. Of the staff that did not blend their module, some indicated they still intend to do so, while there are a variety of reasons why others did not continue. Many staff joined the BL movement but were not included in the pilot to make the analysis more manageable. For example, in CoE alone, more than 50 academic staff members are now integrating BL into their learning and teaching provision. Over 6,550 students experienced at least one blended module as a direct result of the pilot in the 2017/2018 academic year.

Examination of the quantitative data has produced no conclusive institutional trends when studying student attendance, exam performance and module evaluation scores on blended modules against baseline data from previous years. For example, $52 \%$ of the 92 modules showed an increase in mean module assessment result, while $48 \%$ showed a decrease. There are so many factors at play; this was not a surprising result when considering this was data representing change over just one year. Experience gleaned from the work of blended learning pioneers shows that it sometimes takes several years of reflective practice to achieve consistently improved markers of student engagement and understanding. However, one of the many positives arising from the pilot is the creation of a data set and methodology to perform a meaningful longitudinal study in future years.

\subsection{Student Feedback and Experience}

Student feedback was taken via the existing module feedback system utilised at Swansea University and all comments and responses anonymised. Quantitative data that shows student perception of online materials, quality of module and quality of lecturer's teaching were on average higher for pilot participants than the general population. While the data did not measure change from year to year it does indicate that the adoption of blended learning can be encouraged at institutional level without detrimental effects to the student experience or key performance indicators at least in the short term. However, when examining this data consideration must also be given to the way that academic staff volunteered to be pilot participants and it is possible that digitally capable staff, with confidence in their teaching practice volunteered to cause a self-selecting type bias to the results.

The examination of the qualitative data in the form of student comments in anonymised module feedback demonstrates the same positive reception seen by early adopters. A comment typical of many is: -

"I enjoyed how lecturers used a lot of engaging resources such as videos, podcasts, among others, to share the content in a more fun, interactive way. The labs were also very effective in my opinion and made me feel like I was applying my knowledge. Both XXXX and XXXX did a good job at structuring the module in a nice, logical way that made it easy for me to follow through".

It was encouraging that some students were also aware of one of the benefits of blended learning in encouraging independent learning. Another typical comment was: -

"Self-study resources provided by XXXX were really useful and I appreciate that I could prepare for the lecture beforehand. This way, I was more active and I could focus more on understanding the more complicated concepts rather than make notes". 
Clearly best practice in blended learning is already emerging from the academic volunteers that can be shared and improved further with reflective practice.

Part of the student module feedback questionnaire asks students to comment on what aspects could be improved and provided students with an opportunity to add comments that might be considered more negative or constructive, and some indicated that they still preferred traditional lectures for example: -

"I didn't enjoy the seminar style lectures or the e-lectures. XXXX was a very good lecturer and I feel I could have learnt more with standard style lectures."

The lecturer in question will need to consider whether blended learning is the best approach in the module or question if this view is more isolated and there are ways to adapt the learning activities and use this feedback to improve the educational design. Reflective practice to consider student feedback is important and addressing concerns by further interventions is an ongoing iterative process. The majority of the comments focusing on what could be improved were generally about specific issues with accessing materials, formatting and layout for example: -

"The way lecture notes are presented on blackboard is not intuitive, fiddly and hard to get what you want. I like the inclusion of you tube videos but it would be nice to have a play list link so I can access it quickly instead of struggling to get to them through the LMS"

They can, therefore, be considered useful constructive criticism of specific practice rather than a criticism of the use of blended learning as a pedagogic approach.

To summarise, in general, both the quantitative and qualitative feedback data shows that most students at Swansea University value blended learning and would like more adoption across the University. Where negative comments are seen it is more usually focused on specific issues with instructional design rather than an objection to the use of technology. In hindsight, one of the lessons learned is that the project would have benefitted from more student input into the design of the pilot itself and to help in the operational phase. Collective student voice is vital to ensure that all viewpoints are seen and heard to ensure project success.

\subsection{Staff Feedback}

The academic staff volunteers gave feedback in the form of an exit survey distributed in January 2019. Fifty-three volunteers contributed to the survey, with the results being used to inform the final figures contained in this document. Survey questions focused on the module, the development experience, individual professional development, and their impressions of the impact on the students.

From the volunteers that engaged with this survey, $92.5 \%$ indicated they would blend future modules, and $7.5 \%$ of volunteers indicated they were not sure if they would blend in future. There were no volunteers that indicated they would not engage in future blending.

\subsubsection{Analysis of Blend Percentages}

In terms of the type of blend achieved, volunteers were asked to estimate the ratio of face-to-face versus online blend. Fig 1 depicts their responses, indicating a favouring towards face-to-face percentages, with smaller steps towards online delivery in most incidences. Several volunteers expressed a desire to develop further online content and more of a 50:50 hybrid model, however, cited challenges in terms of development time and current workload impacting their ability to achieve this blend within realistic timeframes. 


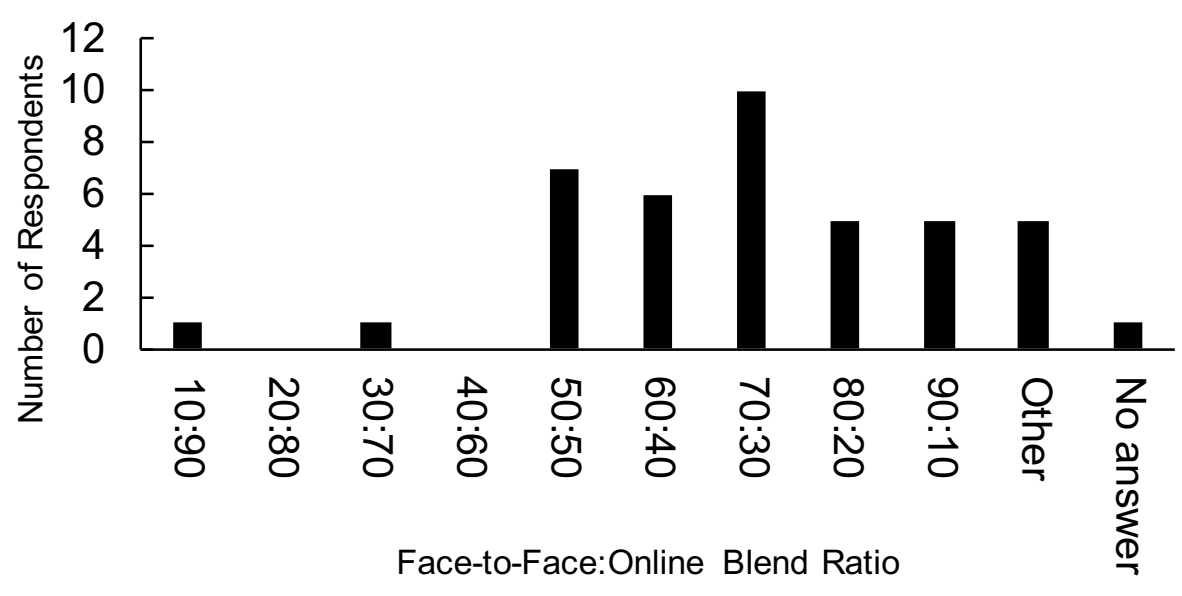

Figure 1. Blending Ratios

\subsubsection{Time Required to Blend Modules}

Different approaches to the development of blending were evident; volunteers were asked to estimate the amount of time it had taken to blend their module. Fig 2 below charts those responses, indicating a month to two months was the average time frame required.

- Number of respondents

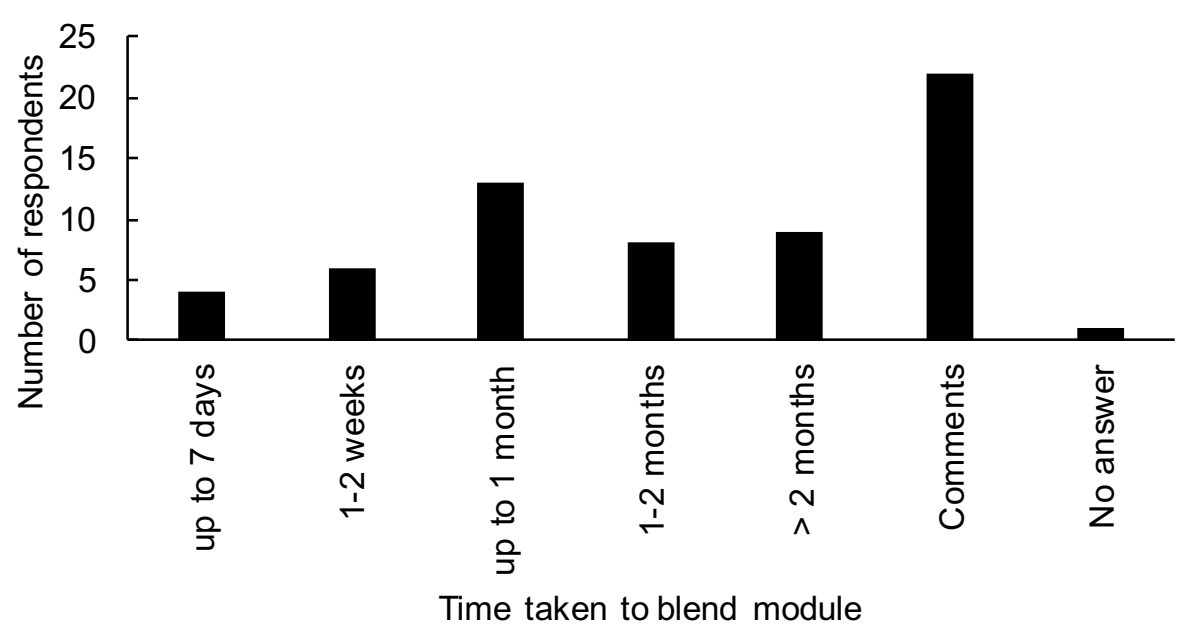

Figure 2. Blended Module Development Timeframe

While Fig 2 helps determine the period over which academics worked on their blended content, it does not determine the number of hours or days required to create the content. For example, how many hours of work is required to create one hours-worth of online study material? Further work with a more detailed survey or other feedback mechanisms such as focus groups would have been a useful contribution to this study and should be considered by other institutions considering initiating similar projects.

\subsubsection{Staff Development, Recognition and Reward}

One of the most rewarding aspects of the Blended Learning Pilot was its success in helping develop academic staffs' digital skills and providing evidence for recognition. Qualitative data in the form of staff responses in the final survey show that 31 staff volunteers thought that their new knowledge and experience in blending helped to advance their practice while 21 staff had used their evidence of success to support an application for Higher Education Academy (HEA) Fellowship or promotion applications. The Blended Learning Pilot also resulted in many academic publications. Independently, 
eight staff presented at the 2018 HEA STEM Conference in addition to invited talks and workshops across the sector.

One area of staff feedback that became particularly apparent during the delivery of the pilot was that the training provided was focused on the use of technology. Staff requested that training on the pedagogical approach to the best use of blended learning would be valuable. The team found best practice in the sector to be the University College London, Arena Blended Curriculum (ABC) design workshops and used the free toolkit to provide the training requested to support specific College requests and on-board additional volunteers in a second phase of the project [11].

\subsubsection{Analysis of Additional Staff Comments}

Analysis of staff feedback comments shows that the pilot was positively perceived. Some staff comments focused on how blended learning approaches can help support professional values such as accessibility and inclusivity. For example, the following feedback focuses on diversifying student experience and accessibility: -

"Consider it carefully. It is an excellent way of diversifying student experience while ensuring that modules are accessible for those who have difficulties regularly travelling to a campus (this can be for a variety of reasons, particularly where adult learners are concerned)".

Other common areas of focus included flexible and independent learning for example:

"Blended Learning helps students work through material at a pace that suits them. It also improves my sense of connection to the students; I can see who is and isn't engaging throughout. When students come for support, I can target my advice to how far through the material they have worked. I would advise giving the students weekly summaries to remind them at which stage of the work they should be, give them feedback on their progress so far."

Staff also gave various feedback on how the institution could support and improve the introduction of blended learning including:

"Great pilot and extremely important way of engaging students and making content more inclusive but we need many more trained technology experts to provide support", "I think BL has a lot to offer and but I think this needs to be a 'top down' process where management know what is going on in each module and encourage consistency" and "This was an excellent University wide project that encouraged collaboration and excellence in teaching. It should continue with a permanent team and resources to support other academics who wish to try out new ideas".

The feedback from staff was particularly insightful into developing strategies for further adoption and to create a framework to support blended learning. Additional staff feedback was gained about the range of software tools they employed in their delivery which was important when specifying the functionality of the new Learning Management System (LMS) that will be brought online for the 2020/2021 academic year.

\subsection{University Governance Changes}

During the delivery of the pilot, it became increasingly clear that it was difficult to find investment and human resources for implementation and ongoing support of TEL software and systems such as Camtasia $^{\mathrm{TM}}$. Feedback from our students and staff indicated our LMS may be dated and should be reviewed and that lecture capture was desirable for accessibility and inclusivity aspects. While conversations across the institution showed that the intention was there, there was no apparent mechanism to find investment and resource to take these large projects forward. Our project manager realised there was a gap in the institutional governance of TEL and compared to investment in the physical estate there was insufficient investment planned to enable adoption of blended learning. To correct this issue the Blended Learning Pilot Team formed a TEL Board with cross-institutional and senior membership to provide institutional governance of TEL.

This step proved to be highly valuable and created funding for and approval of significant projects such as a tender and acquisition of a new LMS. One of the successes of this pilot project is it demonstrates that teamwork, collegiality, student and staff voice and goodwill can provide bottom-up impetus to change institutions and their structures. 


\subsection{Ripple Effects}

\subsubsection{The International Virtual Reality Learning and Teaching Conference at Swansea University}

Our CoE champion and pilot co-lead focused efforts on VR. Due to the success of these interventions and recognising the absence of targeted VR conferences specifically focussing on enhancing learning and teaching, it was decided to organise and host one at Swansea in September 2018, titled "Virtual and Augmented Reality to Enhance Learning and Teaching in Higher Education". This was highly successful with two world-leading Keynote speakers, 18 paper presentations and a number of poster presentations and interactive VR/AR demonstrations. The conference proceedings are now available [12]. The opening keynote speaker noted that the CoE at SU is probably the first in the UK that is comprehensively embedding VR in its programmes for all of its students.

Establishing an international VR conference has motivated the learning communities across Swansea University and created new national and international networks. The pilot has demonstrated that through university-wide teamwork and collegiality, institutions can move quickly to advance new pedagogical approaches and have impact across the wider sector. However, careful thought must be given to planning for how to maintain effort and trajectory, and this is now the focus of Swansea University staff going forward.

\subsubsection{The Growing Comms Project}

During the pilot project staff innovated with new pedagogic approaches. The move to active learning led to increased use of the 'flipped classroom', highlighting space limitations in terms of flat floor active learning spaces. Two of the project team visited Texas A\&M, Swansea University's largest strategic partner who had just finished building the Zachry Engineering Education Centre, dedicated to a change to new pedagogies, delivered in active learning studios [13]. Prompted by the visit to Texas, an opportunity arose to bring the Sticky Campus Roadshow to Swansea and used it for teaching modules on the pilot [13]. The Roadshow was influential and working across the institution in multidisciplinary teams have enabled the first dedicated flexible digital classrooms to be realised at Swansea University.

Building on the success of the Blended Learning Pilot and learning from the use of active classrooms Swansea University has been awarded funding from HEFCW for a project called Growing Regional Outputs With Innovative Next Generation Communications (Growing Comms) designed to enhance HE-FE collaboration. The project is designed to link active learning spaces with communication platforms to create opportunities for combinations of synchronous and asynchronous approaches for 'active distance learning'. Innovation events will be used to prepare Further Education (FE) students for visits to SU to help encourage HE study. Innovative activities are underway, and for example FE Spanish Language students are working collaboratively with students and staff in the University's languages department. Through sharing approaches to blended learning, the start of organic regional blended learning collaboration and alignment is emerging.

\section{CONCLUSIONS AND FURTHER WORK}

\subsection{General Conclusions}

In this paper, we present the Swansea University Blended Learning Pilot project. The pilot was established to improve the effectiveness of teaching, provide an institutional framework and roadmap to blended learning. It has achieved its aims and additionally created innovation, activity and new networks beyond the institution. The blended learning pilot also formed part of Swansea University's successful TEF Gold application of 2018.

The design of the Blended Learning Pilot was such that it maintained the previous spirit and freedom of the organic growth adding institutional support to maintain the natural innovation and departmental ownership. Staff volunteers wanting to trial blended learning were encouraged, trained and given access to appropriate tools.

The project results show the benefits of this approach where each academic expert decided on the type and extent of blended learning activity, tailoring it specifically for purpose. Using this approach in any further institutional growth in tandem with alternative design approaches, such as UCL's (2018) 
Arena Blended Curriculum will help mitigate risks associated with consistency of practice. The handsoff, unstructured approach and institutional scale give some indicative quantitative data on factors such as the relationship between attendance and performance. Controlled studies are required for a detailed and accurate analysis and understanding, although this would need to be a longitudinal study to account for the iterative nature of continuous improvement through staff reflective practice.

\subsection{Recommendations and Further Work}

The recent acquisition of a new LMS has helped highlight the importance of a considered approach to blended learning growth. Swansea University is now considering the five recommendations from the Blended Learning Pilot project report to support strategic growth. Blended learning has been highlighted as an area for development in the University's new learning and teaching strategy.

\subsubsection{Recommendation 1 - Strategic Alignment}

The successful development and implementation of further blended learning requires a coordinated, collaborative and strategic approach throughout the institution.

\subsubsection{Recommendation 2 - Programme Level Blending}

An embedded programme level approach is required to support the development of student digital literacy, outlining how blending is introduced and evolves over an academic programme and how the use and development of technology and digital literacy supports this agenda for both staff and students.

\subsubsection{Recommendation 3 - Blended Learning Training}

A training and development package should exist to support academics and professional services staff wanting to engage with and develop blended learning.

\subsubsection{Recommendation 4 - Personnel Requirements}

To ensure effective support for the implementation of blended learning approaches an appropriate staffing structure is required. A lead is required to coordinate the strategic approach to development with campus-wide collaboration, ensuring the training and development needs of all staff are met.

\subsubsection{Recommendation 5-Growth Opportunities and Maximising Capacity}

Blended learning has the potential to support timetabling and physical capacity pressures. Specific consideration could be given to the use of generic blended module content.

\section{ACKNOWLEDGEMENTS}

The authors would like to thank all the students and academic staff at Swansea University who participated in the Blended Learning Pilot project. We want to acknowledge Professor Martin Stringer, who sponsored the project; the Heads of Colleges who funded it; the academic champions, Ruth Costigan, Paul Davies, Neal Harman, Rebecca Pratchett and Matthew Stevens. We would also like to thank all the professional services staff across the University for their continuous support for learning and teaching.

\section{REFERENCES}

[1] Jisc, Mobile Learning, United Kingdom, 12 November 2015.

[2] T. B. Newman, Helen, and S. Knight, "Digital experience insights survey 2018: findings from students in UK further and higher education," Jisc, 2018.

[3] R. Adams, "Almost half of all young people in England go on to higher education," The Guardian, 2017.

[4] UCAS. "A record percentage of young people are off to university," 23 September 2019, 2019; https://www.ucas.com/corporate/news-and-key-documents/news/record-percentage-youngpeople-are-university. 
[5] D. Ford, "Participation Rates In Higher Education: Academic Years 2006/2007 - 2016/2017," D. f. Education, ed., 2018.

[6] UCAS. "Undergraduate tuition fees and student loans," 23 September 2019, 2019; https://www.ucas.com/finance/undergraduate-tuition-fees-and-student-loans.

[7] C. o. t. Exchequer, "Autumn Statement 2013," H. Treasury, ed., The Stationery Office, 2013, p. 99.

[8] O. f. Students. "Teaching Excellence and Student Outcomes Framework," 23 September 2019, 2019; https://www. officeforstudents.org.uk/for-students/the-tef/.

[9] R. Sullivan-Jones, "How the UK HE sector functions as a market, and why it warrants analysis," Times Higher Education, Times Higher Education, 2017.

[10] S. Inge, "University degree or degree apprenticeship: which post 18 option is best?," The Telegraph, 2019.

[11] C. Young, and N. Perovic. "ABC LD toolkit 2018," 23 September 2019, 2019; https://blogs.ucl.ac.uk/abc-Id/home/abc-ld-toolkit/.

[12] Various. "Proceedings of the Virtual and Augmented Reality to Enhance Learning and Teaching in Higher Education Conference 2018," https://www.impopen.com/vrar2018.

[13] Jisc. "Sticky campus roadshow," 26th September 2019, 2019; https://www.jisc.ac.uk/rd/projects/sticky-campus-roadshow. 